\title{
Kolorektal Kanser Cerrahisi Sonrası Önemli Bir Sorun: Fekal İnkontinans
}

\section{An Important Problem After Colorectal Cancer Surgery: Fecal Incontinence}

\author{
Dilek Aktaş ${ }^{1}$ (iD) Sema Koçaş11 ${ }^{1}$ (D) \\ ${ }^{1}$ Ankara Yıldırım Beyazıt Üniversitesi, Sağlık Bilimleri Fakültesi, Hemşirelik Bölümü, Ankara, TÜRKIYYE
}

Geliş tarihi/ Date of receipt: 01/04/2020 Kabul tarihi/ Date of acceptance: 21/04/2020

(C) Ordu University Faculty of Health Sciences, Department of Nursing, Turkey, Published online 30/04/2020

\section{ÖZ}

Son yıllarda kolorektal kanser tanısı konan hasta sayısının artması ile birlikte kolorektal cerrahi oranı da giderek artmaktadır. Kanser tedavisine bağlı olarak ortaya çıkan bağırsak disfonksiyonu bireylerin defekasyon sorunları ile karşı karşıya kalmasına neden olmaktadır.

Kolorektal cerrahi sonrası sıklıkla karşımıza çıkan sorun fekal inkontinanstır. Bu sorunla karşılaşan bireyler damgalanma, utanma, kontrol kaybı duygusu, tuvalete yetişememe endişesi taşımaktadır. Bu nedenle de bireyler fekal inkontinas yaşadığını çevresindeki diğer bireylerle ve sağlık profesyoneli ile paylaşmaktan çekinmekte ve sosyal ortamlardan uzaklaşmaktadırlar. Sosyal ortamlardan uzaklaşmak, yaşam tarzında meydana gelen değişiklikler ve psikolojik sorunlar, bireylerin yaşam kalitesini olumsuz yönde etkilemektedir. Bu nedenle fekal inkontinans şiddetinin en kısa sürede belirlenmesi ve tedavi edilmesi gerekmektedir. Fekal inkontinans tedavisi için pelvik taban egzersizleri, biyofeedback, elektrik stimulasyonu, diyet düzenlemeleri ve ilaç tedavileri önerilmektedir.

Kolorektal cerrahiye bağlı olarak görülen bu durumda yüksek risk grubundaki hastaların ve uygun tedavi seçeneklerinin belirlenmesinde hemşire anahtar rol oynamaktadır. Aynı zamanda hemşireler fekal inkontinans sorunu yaşayan hastaların fiziksel-psikososyal sorunlar ile baş etmesinde, yaşam şeklinin düzenlenmesinde, boşaltım alışkanlıklarının düzenlenmesinde aktif rol oynamaktadır. Hemşire hastaların eğitim, danışmanlık, bakım rollerini üstlenmektedir.

Anahtar Kelimeler: Kolorektal kanser, cerrahi, fekal inkontinans, hemşirelik

\begin{abstract}
With the increasing number of patients diagnosed with colorectal cancer in recent years, the rate of colorectal surgery is gradually increasing. Bowel dysfunction that occurs due to cancer treatment causes to defecation problems.

The problem that we frequently encounter after colorectal surgery is fecal incontinence. Individuals who encounter this problem have a sense of stigma, shame, loss of control, and anxiety related to reach the toilet. For this reason, individuals are afraid to share their fecal incontinence with other individuals around them and healthcare professionals. They move away from social environments. Moving away from social environments, changes in lifestyle and psychological problems negatively affect their quality of life. Therefore, the severity of fecal incontinence should be determined and treated as soon as possible. Pelvic floor exercises, biofeedback, electrical stimulation, dietary regulations and drug treatments are recommended for the treatment of fecal incontinence.

The nurse plays a key role in determining the high-risk patients and appropriate treatment options in this case which associated with colorectal surgery. At the same time, nurses take an actively involved in coping with physicalpsychosocial problems, in the regulation of lifestyle, and in the regulation of excretory habits of individuals with fecal incontinence problems. It assumes the role of education, counseling, and care of patients. Nurses play the role of education, counseling and care of patients.
\end{abstract}

Keywords: Colorectal cancer, surgery, fecal incontinence, nursing

ORCID IDs of the authors: DA: 0000-0001-7932-0434; SK: 0000-0002-5718-0669

Sorumlu yazar/Corresponding author: Arş. Gör. Dilek AKTAŞ

e-posta/e-mail: dlkakts88@gmail.com

Bu çalışma daha önce 9-13 Nisan 2019 tarihinde gerçekleştirilen XVII. Ulusal Kolon ve Rektum Cerrahisi Kongresi ve X. Kolorektal Cerrahi Hemşireliği Kongresinde poster bildiri olarak sunulmuştur. Bildiri kitabında özet bildiri olarak yayınlanmııştrr.

Attf/Citation: Aktaş D, Koçaşlı S. (2020). Kolorektal kanser cerrahisi sonrası önemli bir sorun: Fekal inkontinans.

Ordu Üniversitesi Hemşirelik Çalışmaları Dergisi, 3(1), 36-43. DOI:10.38108/ouhcd.712645 


\section{Giriş}

Kanser en sık karşılaşılan ölüm nedenleri arasında yer almaktadır. Dünya Sağlık Örgütü (DSÖ) 2018 yılında yaklaşık 9,6 milyon kişinin kanser nedeniyle öldüğünü, kanser nedeniyle ortaya çıkan ölümlerde kolorektal kanserlerin ikinci sırada yer aldığını ve aynı yıl 1.80 milyon kişide kolorektal kanser görüldügünü tahmin etmektedir (WHO, 2018). Ülkemizde ise kolorektal kanserler hem kadınlarda hem de erkeklerde en sık görülen kanser türleri arasında üçüncü sırada yer almaktadır (T.C Sağlık Bakanlığı Sağlık İstatistikleri Yıllığı, 2019). Kolorektal kanserler erken dönemde tespit ve tedavi edildiğinde iyileşme oranı yüksek bir kanser türüdür ve temel tedavi yaklaşımı cerrahidir (T.C Sağlık Bakanlığı Halk Sağlığı Genel Müdürlüğü Türkiye Kanser Kontrol Program1, 2016; Erdil ve Erbaş, 2008).

Kolorektal kanser tedavisinde uygulanan cerrahi, kemoterapi ve radyoterapi gibi yöntemler, pelvik tabandaki kas, sinir ve fasial yapılara zarar vererek bağırsak fonksiyonlarını etkilemektedir (Huang ve ark., 2011; Hirano ve ark., 2011; Koda ve ark., 2009). Özellikle rektum kanseri nedeniyle ameliyat olan hastalarda tümör seviyesinin ve anastomoz seviyesinin otonom sinir, pelvik taban ve anal sfinkter yaralanma riskini arttırması nedeniyle bağırsak fonksiyon bozuklukları daha fazla görülebilmektedir (Fish ve Temple, 2014). Bağırsak fonksiyonlarındaki bozulma bireylerin defekasyon sorunları ile karşılaşmasına neden olmaktadir (Fish and Temple, 2014; Elfeki ve ark., 2019). Nikoletti ve ark. (2008) yapmış oldukları çalışmada kolorektal kanser nedeni ile ameliyat olan hastaların \%71'inin bağırsak alışkanlıklarında değişim yaşadığını belirtmiştir (Nikoletti ve ark., 2008). Emmertsen ve ark. (2013) tarafindan yapılan çalışmada ameliyattan sonra ilk 3 ay hastaların \%58'inde, 12 ay sonrasında ise $\% 45.9$ 'unda ciddi bağırsak disfonksiyonu yaşandığ (Emmertsen ve ark., 2013). Yin ve ark. (2018) tarafından yapılan çalışmada ise rektum kanseri nedeni ile ameliyat olan hastaların \%92'si bağırsak alışkanlıklarında değişim yaşadığını belirtmiştir (Yin ve ark., 2018).
Kolorektal cerrahi sonrası karşılaşılan boşaltım sorunları arasında sık defekasyon, konstipasyon, diyare, acil defekasyon hissi, dışkıyı tam boşaltamama, aşırı gaz, perianal ağrı ve fekal inkontinans yer almaktadır (Nikoletti ve ark., 2008; Tan ve ark., 2019; Emmertsen ve Laurberg, 2012; Elfeki ve ark., 2019). Bunlar arasında en sık karşılaşılan sorun fekal inkontinanstır (Lundby ve Duelund-Jakobsen, 2011). Kolorektal cerrahi uygulanan bireylerde yapılmış çalışmalara bakıldığında CamilleriBrennan ve Steele (2002) hastalarm \%70'inde, Siassi ve ark. (2008) \%50'sinde, Landers ve ark. (2014) \%89'unda, Jeong ve Park (2019) \%44.9'unda fekal inkontinans sorunu yaşandığını belirtmiştir (Camilleri-Brennan ve Steele, 2002; Siassi ve ark., 2008; Landers ve ark., 2014; Jeong ve Park 2019). Kolorektal cerrahi sonrası fekal inkontinans sıklığı yaşa, radyoterapi alma durumuna, tümör seviyesine, uygulanan cerrahi girişime, sinir yaralanması olup olmama durumuna göre değişiklik göstermektedir (Jeong ve Park, 2019; Wallner ve ark., 2008). Yapılan çalışmalar yaşanılan bu sorunun 3 ile 12 ay arasında azalma gösterse de 5 yıla kadar devam edebildiğini bildirmiştir (Lange ve ark., 2007; Siassi ve ark., 2008, Landers ve ark., 2011; Barisic ve ark., 2011).

Gaz ve dişkıyı kontrol etme yeteneğinde bozulma olarak tanımlanan fekal inkontinans bireyin yaşamını fiziksel, sosyal ve psikolojik açıdan olumsuz yönde etkilemektedir. Fekal inkontinans sorunu yaşayan hastalar bu durumu sızıntı, perianal bölgede nem hissi veya iç çamaşırlarında lekelenme olarak belirtmektedirler (Timmermans, 2016). Hassas ve duyarlı bir alan olan perianal bölgenin devamlı olarak dışkı ile temas halinde olması kaşıntı, perianal bölgede ağrı, irritasyon ve perianal ülser sorunlarını beraberinde getirmektedir (Dedeli ve Pakyüz, 2016). Bireyler günlük yaşamlarında utanma, damgalanma, tuvalete yetişememe endişesi ve akut inkontinans geçirme korkusu yaşamaktadır. $\mathrm{Bu}$ nedenle aktivitelerini sinırlandırmakta, en yakın tuvaletin yerini sürekli bilmek istemekte, sosyal ortamlardan kaçınmaktadırlar (Simpson ve Whyte, 2006). Fekal inkontinans nedeniyle yaşanılan sorunlar 
sosyal izolasyona, strese, kontrol kaybı duygusuna, öfkeye, anksiyeteye ve depresyona yol açmaktadır (Dedeli ve Pakyüz, 2016). Fekal inkontinansı olan bireyler beslenme alışkanlıklarını değiştirerek, koruyucu pedler kullanarak, ev dişında zaman geçirmek konusunda planlama yaparak sorunlarla başa çıkmaya çalışmakta ve sonucunda yaşam tarzlarını değiştirmektedirler. Fekal inkontinansa bağlı ortaya çıkan tüm bu fiziksel, psikososyal sorunlar ve yaşam şekli değişiklikleri bireylerin yaşam kalitesinin düşmesine neden olmaktadır (Y1lmaz ve Aslan, 2018; Landers ve ark., 2012). Fekal inkontinansa bağlı ortaya çıkan sorunları azaltmak ve bireylerin kendilerini güvende hissetmelerini sağlamak için sorunun erken dönemde saptanıp tedavi edilmesi gerekmektedir. Bu nedenle de hastanın ayrıntılı değerlendirilmesi ve tedavi yönteminin belirlenmesi gerekir (Ness 2012; Lundby ve Duelund-Jakobsen, 2011).

\section{Fekal İnkontinansın Değerlendirilmesi Hasta Öyküsü}

Hemşire bireylerden risk faktörleri, inkontinansa etki edebilecek kronik hastalık, inkontinans ataklarının sıklığı, koruyucu ped kullanımı, genel bağırsak alışkanlıkları, dışkı sıklığı ve yoğunluğu hakkında ayrıntılı bilgi almalıdır. Fekal inkontinans belirtilerini belirleyebilmek, şiddetini ölçebilmek ve bu durumun yaşam kalitesine olan etkilerini belirleyebilmek için skorlama endeksleri ve ölçekler kullanılmaktadır (Hayden ve Weiss, 2011).

Ülkemizde fekal inkontinans şiddetini değerlendirebilmek için Türkçe geçerlilik ve güvenilirlik çalışması yapılmış Wexner Skalası ve Fekal İnkontinans Ciddiyet İndeksi kullanılmaktadır. Wexner Skalasi; Jorge ve Wexner tarafından 1993 yılında geliştirilmiş, 2011 yılında Cam ve arkadaşları tarafından Türkçe geçerlilik çalışması yapılmıştır. Wexner skorlama sisteminde bireyler 0-20 arasi puan almaktadır ve 1 veya daha fazla puan alan hastalar fekal inkontinansli olarak değerlendirilmektedir (Tablo 1) (Cam ve ark., 2011). Fekal İnkontinans Ciddiyet İndeksi ise;
1999 y1lında Rockwood ve arkadaşları tarafından geliştirilmiş olup Türkçe geçerlilik ve güvenilirliği Dedeli ve arkadaşları tarafindan yapılmıştır (Dedeli ve ark., 2009). İndeksten alınabilecek puanın yüksek olması ciddi inkontinansı; puanın düşük olması inkontinansın olmadığını göstermektedir (Tablo 2) (Dedeli ve ark., 2009; Dedeli ve Pakyüz 2016). Ülkemizde kolorektal kanser cerrahisi geçiren bireylerin yaşam kaliteleri değerlendirilmesinde kullanılabilecek Türkçe geçerlilik ve güvenilirlik çalışması yapılmış ölçekler ise Avrupa Kanser Tedavi ve Organizasyon Komitesi Yaşam Kalitesi ölçeği2004 (EORTC-QLQ-C30), K1sa Form-36 Yaşam Kalitesi Ölçeği (SF-36), Fekal İnkontinans Yaşam Kalitesi Ölçeği'dir (Güzelant ve ark., 2004; Pınar, 2005; Dedeli ve ark., 2009).

\section{Tanı Yöntemleri}

Fekal inkontinansin tedavi yönetiminin belirlenebilmesi için tanı yöntemlerinden yararlanılmaktadır (Wang ve Abbas, 2013). Fekal inkontinans değerlendirilmesinde kullanılan tanı yöntemleri aşağıda yer almaktadir.

Anorektal Manometri: Anal kasların rahat iken ve sikma durumunda ne kadar kasılabildiğini belirlemek amaciyla uygulanmaktadır. Aynı zamanda bu test ile anüsün, rektumun hassasiyeti, refleksleri ve genişleme kapasitesi değerlendirilmektedir (Santaro ve ark., 2010).

Tablo 1. Wexner Skalas1

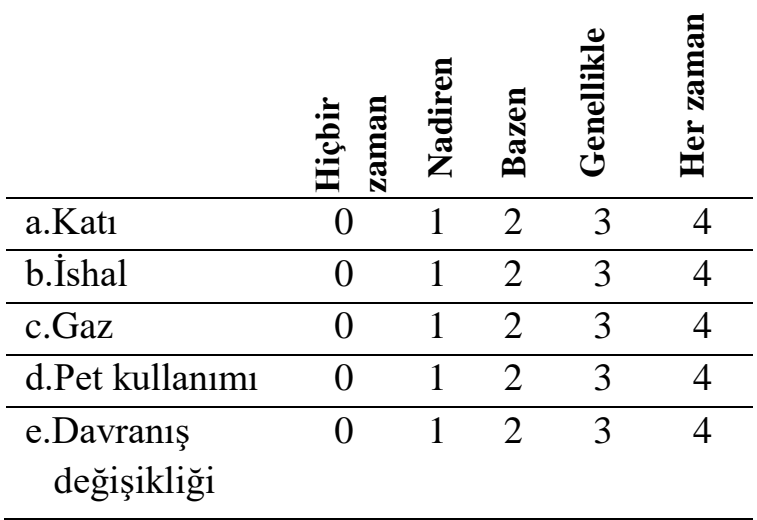


Tablo 2. Fekal İnkontinans Ciddiyet İndeksi

\begin{tabular}{lcccccc}
\hline & $\begin{array}{c}\text { Günde } \\
\text { 2 defa } \\
\text { ya da } \\
\text { daha fazla }\end{array}$ & $\begin{array}{c}\text { Günde } \\
\mathbf{1} \text { defa }\end{array}$ & $\begin{array}{c}\text { Haftada } \\
\text { 2 defa ya } \\
\text { da daha } \\
\text { fazla }\end{array}$ & $\begin{array}{c}\text { Haftada } \\
\mathbf{1} \text { defa }\end{array}$ & $\begin{array}{c}\text { Ayda } \\
\mathbf{1} \text { ile 3 } \\
\text { defa }\end{array}$ & Hiçbir zaman \\
\hline Gaz & $12 / 19$ & $11 / 8$ & $8 / 6$ & $6 / 4$ & $4 / 2$ & 0 \\
\hline Sümük & $12 / 11$ & $10 / 9$ & $7 / 7$ & $5 / 7$ & $3 / 5$ & 0 \\
\hline Sıvı dışkı & $19 / 18$ & $17 / 16$ & $13 / 14$ & $10 / 13$ & $8 / 10$ & 0 \\
\hline Katı dışkı & $18 / 19$ & $16 / 17$ & $13 / 16$ & $10 / 14$ & $8 / 11$ & 0 \\
\hline
\end{tabular}

Hasta/Hemşire

Pudendal Sinir Motor Latensi Testi: Pelvik taban kaslarının ve anal sfinkterlerin sinirsel fonksiyonlarını değerlendirmek amacıyla uygulanmaktadır. Pudendal sinir bir elektrot aracılığ 1 ile uyarılarak kasın kasılması sağlanır ve sinir iletimi değerlendirilir (Santaro ve ark., 2010).

Elektromiyografi (EMG): Diş anal sfinkterin istirahat halinde, s1kma ve refleksif kasılma sırasında, simüle edilmiş dışkılama sırasında kas elektriksel aktivitesinin değerlendirilmesi için kullanılmaktadır (Santoro ve ark., 2010).

Endoanal Ultrosonografi (USG): Endoanal USG, anal sfinkter bütünlügünü ve hasarlarını tanımlamada yardımcı olmaktadır. Anal kanalın anatomisini açıkça gösterir ve rektum, rektal duvar, puborektalis kası, iç ve dış sfinkter, perine kasları görselleştirilir (Santoro ve ark., 2010).

Manyetik Rezonans Görüntüleme (MRG): Pelvik tabanın karmaşık anatomisini anlamak ve pelvik taban bozukluklarını değerlendirmek için kullanılmaktadır. Pelvik taban anatomisi hastayı zararlı iyonlaştırıcı radyasyona maruz bırakmadan ayrıntılı olarak görselleştirilebilir. Ayrica fonksiyonel pelvik taban anormalliklerinin ve özelliklerinin saptanmasina izin verir (Santoro ve ark., 2010).

\section{Fekal İnkontinans Tedavi Yöntemleri}

Diyet: Diyet yönetiminde amaç ideal dışkı yoğunluğunu sağlamak ve dışkı geçiş hızını azaltmaktır. Kahve, lifli besinler, baharatlı yiyecekler, tatlandırıcı içeren ürünler diyareye yatkınlığ 1 arttırırken, yeşil sebzeler, soğan ve mantar dışkı geçişini hızlandırmaktadır. $\mathrm{Bu}$ nedenle bu besinlerin tüketimi sinırlandirılmalıdır. Croswell ve ark. (2010) ve Hansen ve ark (2006) tarafindan yapılan çalışmalarda katılımcılar fekal inkontinans şikayetlerini arttıran yiyecekler arasında siklıkla sebzeleri, baharatlı yiyecekleri, meyveleri, yağlı yiyecekleri, kafein içeren yiyecekleri ve süt ürünlerini belirtmiştir (Croswell ve ark, 2010; Hansen ve ark, 2006). Aynı zamanda bireyler kendileri de inkontinans sıklığını artıran besinleri tespit ederek diyetlerinde değişikliğe gitmelidir (Ness, 2012).

Pelvik Taban Kas Egzersizleri: Egzersiz sayesinde pelvik taban ve anal sfinkter kaslarının istemli olarak kasılma ve gevşemesi sağlanarak latent motor ünite aktive edilir. Böylece kasa fonksiyonelliği yeniden kazandırılır (Akbayrak ve Kaya, 2016). Pelvik taban kas egzersizleri yavaş ve hızlı kasılan kas lifleri için endurans (dayanıklılık) egzersizlerini, güç kuvvet egzersizlerini içermelidir (Akbayrak ve Kaya, 2016). Egzersizler uygulanırken ilgili kasların aktivasyonunun sağlanmasına, sırt, gluteal, addüktör kasların kasılmamasına ve düzenli olarak uygulanıp yaşam boyu sürdürülmesine dikkat edilmelidir (Akbayrak ve Kaya, 2016; Cangöl ve ark., 2013). Aynı zamanda pelvik taban kasları her seferinde en fazla 10 saniye kasılmalı ve 10 saniye öncesinde kas yorgunluğu gözlemlendiği anda olursa kas serbest birakılmalıdır. Dinlenme halindeki kas tonüsünün artırılması için egzersizlere 12-24 hafta devam edilmelidir (Moore, 2013). Lin ve ark. (2016)'nın stoması kapatılan bireyler ile 
yapmış oldukları çalışmada pelvik taban egzersizlerinin fekal inkontinansin azaltılmasında etkili olduğu saptanmıştır.

Biyofeedback: Biyofeedback pelvik taban ve anal sfinkter kaslarının çalıștırılması, abdominal, gluteal ve anal sfinkter kasları arasındaki koordinasyonun geliştirilmesi, anorektal bölgedeki duyusal algının arttırılması amaciyla uygulanmaktadır (Wang ve Abbas, 2013). Hastaya anal sfinkter basincinı ve aktivitesini gösterme imkânı tanır. Aynı zamanda anal sfinkter egzersizlerinin etkin bir şekilde öğretilmesini ve bireye geri bildirim verilmesini sağlamaya yardımcı olur. Sıkışma kuvvetini ve enduransını (dayanıklılığını) arttırmada bireyi teşvik etmek için işlem sırasında görsel ve işitsel sinyaller kullanılabilir. (Akbayrak ve Kaya, 2016). Heymen ve ark. (2009) yaptıkları çalışmada pelvik taban kas egzersizlerinin biyofeedback ile yaptırılmasının fekal inkontinansın tedavisinde daha etkili olduğunu belirtmiştir (Heymen ve ark, 2009).

Elektrik Stimülasyonu: Pelvik taban kaslarının, sfinkterlerin ve sinir yapılarının pasif olarak uyarılması sağlayan elektrik stimulasyonu, uyarılan kasların izole kontraksiyonunu ve farkındalığını arttırarak pelvik taban kaslarının yeniden eğitilmesini sağlar (Akbayrak ve Kaya, 2016). Ancak elektrik stimülasyonu anal enfeksiyonlar, rektal kanama, pelvik taban kaslarının tam denervasyonu (sinir iletiminin kesilmesi), ödemli ve ağrılı hemoroidler, duyu bozukluğu, mukoza atrofisi, kalp pili, demans, gebelik, ağr1lı palpasyon durumunda ve cerrahiden sonra ilk 6 hafta uygulanmamalıdır (Akbayrak ve Kaya, 2016).

İlaç Tedavisi: Farmakolojik tedavi olarak en sik Loperamid HCL tercih edilmektedir. Loperamid HCL barsak hareketliliğini engelleyerek dışkı yoğunluğunu değiştirmeye yardımcı olur. Dışkıdan sıvı geri emilimini artırmak ve bağırsaktan geçişi yavaşlatmak için ise Amitriptilin'in antikolinerjik etkisinden yararlanılmaktadır. Acil defekasyonu önlemek için antispazmotikler, tam boşalmayı sağlayabilmek ve pasif inkontinansı önlemek için ise gliserin fitilleri tercih edilebilir (Ness, 2012).

Cerrahi Tedavi: Fekal inkontinans sorunu konservatif tedavi yöntemleri ile tedavi edilemediğinde anal sfinkter rekonstrüksiyonu uygulanmaktadir (Lundby ve DuelundJakobsen, 2011; Wang ve Abbas, 2013). Şiddetli fekal inkontinansı olan hastalarda ise stoma açilabilmektedir (Lundby ve DuelundJakobsen, 2011) .

\section{Kolorektal Cerrahi Sonrası Fekal İnkontinas Yönetiminde Hemşirelik Bakımı}

Kolorektal kanser cerrahisi geçiren bireyler ameliyat sonrası bağırsak fonksiyonunda meydana gelen değişiklikleri yönetmek için desteğe ihtiyaç duymaktadır (Landers ve ark., 2012). Bu nedenle hemşireler sağlıklı bağırsak boşaltımını sürdürmek için bireye özgü bir hemşirelik bakımı sağlamalıdır (Dedeli ve Pakyüz, 2016). Aynı zamanda hemşireler fekal inkoninans yönünden yüksek riskli bireyleri belirlemede, uygun tedavinin belirlenmesinde ve bağırsak fonksiyonunu iyileştirici yöntemlerin öğretilmesinde önemli bir rol oynamaktadır (Gump ve Schmelzer, 2016).

Fekal inkontinans doğru tanılama ve iyi bir tıbbi yaklaşımla tedavi edilebilir bir durumdur (Yılmaz ve Aslan, 2018). Doğru tanılamanın yapılabilmesi için hemşire, ayrıntılı bir hasta öyküsü almalı, ölçeklerden yararlanarak fekal inkontinansın şiddeti ve yaşam kalitesine etkisini değerlendirmelidir (Dedeli ve Pakyüz, 2016). Doğru bir tanılamanın sonrasında hastaya uygun tedavi şeklinin belirlenmesi gerekmektedir. Hemşire bu süreçte hastalara konservatif tedaviler konusunda danışmanlık yapmalı, pelvik taban ve anal kasları güçlendiren egzersizleri öğretmeli, düzenli tuvalet alışkanlığını kazandırmalı, yaşam şeklinin düzenlemesi konusunda hastalara eğitim verilmeli ve tedavi süresince hastaları desteklemelidir (Y1lmaz ve Aslan, 2018). Hasta öyküsü alma, danışmanlık ve eğitim sırasında, hastanın eğitim seviyesine uygun, açık ve anlaşılır bir dil kullanmalıdır (Timmermans, 2016).

Hastalar ameliyat sonrasında bağırsak fonksiyonlarının nasıl etkileneceği, sorunların 
ne kadar devam edeceği konusunda bilgilendirmeye ihtiyaç duymaktadır (Landers ve ark., 2012). Bu nedenle hastalara ameliyat sonrasında oluşabilecek sorunlar hakkında bilgilendirme yapılmalıdır. Ameliyat öncesinde hastalara verilen sözlü bilgiler yazılı materyallerle de desteklenmelidir (Taylor ve Morgan, 2011). Bireyler kolorektal cerrahi sonrasında bağırsak alışkanlıklarını düzenlemek için diyet ve sosyal aktivite zamanlarına göre yemek zamanını planlamak, tuvalete yakın oturmak, egzersizden kaçınma gibi davranış değişikliklerine başvurmaktadır (Sun ve ark., 2015). Bu nedenle hemşire, bireylerin fekal inkontinans şiddetini azaltmak için neler yaptıklarının, fekal inkontinansa bağlı sorunlarla nasıl başetmeye çalıştıklarının ve yaşamlarının nasıl etkilediğinin farkında olmalıdır. Hastalara gıdaların etkileşimi, diyetler, ilaçların doğru kullanımı hakkında bilgi vermelidir (Nikoletti ve ark., 2008).

İnkontinans ile ilişkili dermatit, fekal inkontinansl h hastalarda meydana gelen ve bireyi rahatsiz eden bir sorundur. Dermatit bireylerin fiziksel ve psikolojik sorunlar yaşamasına neden olmaktadır. Dermatiti önlemek için hemşire, hastanın risk değerlendirmesini yapmalıdır. Dermatit gelişimini önlemek için cildin temiz ve kuru tutulmasını sağlamalı, cilt temizliğinde $\mathrm{pH}$ 'ı cilt pH'na yakın ürünler kullanılmalıdır (Bardsley, 2013; Beeckman ve ark., 2009). Cilt temizliğinde genel olarak su ve sabun kullanılması önerilmektedir. Bunların yanında cilt bütünlügünü korumak için cilt koruyucu ürünler de kullanılabilir (Beeckman ve ark., 2009).

Bireyler utanma, damgalanma, tuvalete yetişememe korkusu gibi nedenlerle sosyal ortamlardan kaçınmakta, durumlarını gizlemek istemektedir (Landers ve ark., 2012). Bu yüzden bireylere psikolojik ve sosyal uyum desteği sağlamalıdır (Yılmaz ve Aslan, 2018). Uygun terapötik destek şeklini belirleyebilmek ve fekal inkontinans yönetiminde verilen önerilerin hasta tarafından kabulünü kolaylaştırmak için hastaların duygusal tepkilerin farkında olması önemlidir (Patel ve ark., 2010). Aynı zamanda hemşire, bireylerle iletişim kurarken empati kurmalı ve damgalamadan kaçınmalıdır (Timmermans, 2016).

\section{Sonuç ve Öneriler}

Kolorektal cerrahi sonrası fekal inkontinans ciddi bir sorun olarak karşımıza çıkmaktadır. Bireyler fekal inkontinansa bağlı fiziksel ve psikososyal sorunlarla karşılaşmaktadır. $\mathrm{Bu}$ nedenle bireylerin yaşam kalitesi de olumsuz etkilenmektedir. Hemşireler kolorektal cerrahi geçiren hastalarda fekal inkontinans yönünden risk durumunun belirlenmesinde, sorunun erken dönemde tanımlanmasında ve uygun şekilde tedavisinin sağlanmasında önemli sorumluluklar üstlenmektedir. Hemşire bu bireylerin fiziksel-psikososyal sorunlar ile baş etmesinde, yaşam şeklinin düzenlenmesinde, boşaltım alışkanlıklarının düzenlenmesinde eğitim, danışmanlık, bakım rollerini bütüncül bir yaklaşımla yerine getirmelidir. Özelleşmiş olan bu alanlarda çalışan hemşirelerin bilgi düzeyleri ve bu konuya yönelik farkındalıklarını arttırmak için hizmet içi eğitimler düzenlenmelidir.

Araştırmanın Etik Yönü/ Ethics Committee Approval: Kullanılan literatür kaynaklar bölümünde gösterilmiştir.

Hakem/Peer-review: D1ş hakem değerlendirmesi.

Yazar Katkısı/Author Contributions:

Fikir/kavram: Fikir/kavram: DA, SK; Tasarım: DA, SK; Kaynak tarama: DA, SK; Makalenin Yazımı: DA, SK; Eleştirel inceleme: DA, SK.

Çıkar çatışması/Conflict of interest: Çalışmada herhangi bir çıkar çatışması söz konusu değildir Finansal Destek/Financial Disclosure: Herhangi bir finansal destek alınmamıştır.

Çalışma Literatüre Ne Kattı?

- Kolerektal kanser cerrahisi sonrası karşılaşılan bir sorun olan fekal inkontinans hakkında bilgi verilmiştir.

- Fekal inkontinansın değerlendirilmesi ve tedavi yöntemleri belirtilmiştir.

- Kolorektal kanser cerrahisi sonrası fekal inkontinans sorununun yönetiminde hemşirelik bakımı ele alınmıştır.

- Fekal inkontinansta hemşirelik bakımının önemi ve özelleşmiş olan bu alanlarda çalışan hemşirelerin bilgi düzeylerini ve farkındalıklarını arttırmak için hizmet içi eğitimlerin düzenlenmesi gerektiği vurgulanmıştır. 


\section{Kaynaklar}

Akbayrak T, Kaya S. (2016). Kadın Sağlığında Fizyoterapi ve Rehabilitasyon. 1. Bask1, Ankara, Kalkan Matbaac1lik, s. 141-166.

Bardsley A. (2013). Prevention and management of incontinence-associated dermatitis. Nursing Standard, 27(44). 41-46.

Barisic G, Markovic V, Popovic M, Dimitrijevic I, Gavrilovic P, Krivokapic ZV. (2011). Function after intersphincteric resection for low rectal cancer and its influence on quality of life. Colorectal Disease, 13(6), 638-643.

Beeckman D, Schoonhoven L, Verhaeghe S, Heyneman A, Defloor T. (2009). Prevention and treatment of incontinence-associated dermatitis: literature review. Journal of Advanced Nursing, 65(6), 1141-1154.

Cam C, Selcuk S, Asoglu MR., Tug N, Akdemir Y, Ay P, Karateke A. (2011). Validation of the Wexner scale in women with fecal incontinence in a Turkish population. International Urogynecology Journal, 22(11), 1375-1379.

Camilleri-Brennan J, Steele R JC. (2002). Prospective analysis of quality of life after reversal of a defunctioning loop ileostomy. Colorectal Disease, 4(3), 167-171.

Cangöl E, Aslan E, Yalçın, Ö. (2013). Kadınlarda pelvik taban kas egzersizleri ve hemşirenin rolü. Hemşirelikte Eğitim ve Araştırma Dergisi, 10 (3), 49-56.

Croswell E, Bliss DZ, Savik K. (2010). Diet and eating pattern modifications used by communityliving adults to manage their fecal incontinence. J Wound Ostomy Continence Nurs, 37(6); 677682.

Dedeli Ö, Fadiloglu C, Bor S. (2009). Validity and reliability of a Turkish version of the Fecal Incontinence Quality of Life Scale. Journal of Wound Ostomy\&Continence Nursing, 36(5), 532-538.

Dedeli Ö, Pakyüz S.Ç. (2016). Bowel movement: the sixth vital sign?. Clinical and Experimental Health Sciences, 6(3), 135-139.

Emmertsen K.J, Laurberg S. (2012). Low anterior resection syndrome score: Development and validation of a symptom-based scoring system for bowel dysfunction after low anterior resection for rectal cancer. Annals Surgery, 255( 5), 922-928.
Emmertsen K.J, Laurberg S, Jess P, Madsen M.R, Nielsen H.J, Ovesen A.U ve ark. (2013). Impact of bowel dysfunction on quality of life after sphincter-preserving resection for rectal cancer. British Journal of Surgery, 100(10), 1377-1387.

Elfeki H, Larsen H.M, Emmertsen K.J, Christensen P, Youssef M, Khafagy W ve ark. (2019). Bowel dysfunction after sigmoid resection for cancer and its impact on quality of life. British Journal of Surgery, 106(1), 142-151.

Erdil F, Elbaş NÖ. (2008). Cerrahi Hastalıkları Hemşireliği. 5. Bask1, Ankara, Aydoğdu Ofset Matbaacılık Ambalaj San. Tic Ltd. Şti.480-481.

Fish D, Temple LK. (2014). Functional consequences of colorectal cancer management. Surgical Oncology Clinics of North America, 23, 127-149.

Güzelant A, Göksel T, Özkok S. (2004). The European Organization for Research and Treatment of Cancer QLQ-30: An examination into the cultural validity and reliability of Turkish version of the EORTC QLQ-30. European Journal of Cancer Care, 13, 135-144.

Gump K, Schmelzer M. (2016). Gaining control over fecal incontinence. Medsurg Nursing, 25 (2), 97-102.

Hansen JL, Bliss DZ, Peden-McAlpine C. (2006). Diet strategies used by women to manage fecal incontinence. J Wound Ostomy Continence Nurs, 33(1), 52-61

Hayden D.M, Weiss E.G. (2011). Fecal incontinence: etiology, evaluation, and treatment. Clinics in Colon and Rectal Surgery, 24(1), 64-70.

Heymen S, Scarlett Y, Jones K, Ringel Y, Drossman D, Whitehead WE. (2009). Randomized controlled trial shows biofeedback to be superior to pelvic floor exercises for fecal incontinence. Diseases of the Colon \& Rectum, 52(10), 1730-1737.

Hirano A, Koda K, Kosugi C, Kasugi C, Yamazaki M, Yasuda H. (2011). Damage to anal sphincter/levator ani muscles caused by operative procedure in anal sphincter-preserving operation for rectal cancer. The American Journal of Surgery, 201(4), 508-513.

Huang YJ, Lin SE, Wei PL, Hung CS, Kuo LJ. (2011). Histopathologic analysis of the anal sphincter after chemoradiation for low rectal cancer. Journal of Experimental \& Clinical Medicine, 3 (6): 296-269. 
Jeong H, Park J. (2019). Factors influencing changing bowel habits in patients undergoing sphincter-saving surgery for rectal cancer. International Wound Journal, 16(1), 71-75.

Koda K, Yasuda H, Hirano A, Kosugi C, Suzuki M, Yamazaki M ve ark. (2009). Evaluation of postoperative damage to anal sphincter/levator ani muscles with three-dimensional vector manometry after sphincter-preserving operation for rectal cancer. Journel of the American College Surgeons, 208(3), 362-367.

Landers M, Savage E, McCarthy G, Fitzpatrick JJ. (2011). Self-care strategies for the management of bowel symptoms following sphincter-saving surgery for rectal cancer. Clinical Journal of Oncology Nursing, 15( 6), E105- E113.

Landers M, McCarthy G, Savage E. (2012). Bowel symptom experiences and management following sphincter saving surgery for rectal cancer: a qualitative perspective. European Journal of Oncology Nursing, 16(3), 293-300

Landers M, McCarthy G, Livingstone V, Savage E. (2014). Patients' bowel symptom experiences and self-care strategies following sphincter-saving surgery for rectal cancer. Journal of Clinical Nursing, 23(15-16), 2343-2354.

Lange MM, Den Dulk M, Bossema ER, Maas C.P, Peeter K.C.M.J., Rutten H.J ve ark. (2007). Risk factors for faecal incontinence after rectal cancer treatment. British Journal of Surgery, 94( 10), 1278- 1284.

Lin Y.H, Yang H.Y, Hung S.L, Chen, H.P, Liu, K.W, Chen, T. B, Chi S.C. (2016). Effects of pelvic floor muscle exercise on faecal incontinence in rectal cancer patients after stoma closure. European Journal Of Cancer Care, 25(3), 449-457.

Lundby L, Duelund-Jakobsen J. (2011). Management of fecal incontinence after treatment for rectal cancer. Current opinion in supportive and palliative care, 5(1), 60-64.

Moore K.H. (2013). Urogynecology: Evidence-Based Clinical Practice. 2. Bask1, London, Springer Science \& Business Media, 81-82.

Ness W. (2012). Faecal incontinence: causes, assessment and management. Nursing Standard, 26(42). 52-60.

Nikoletti S, Young J, Levitt M, King M, Chidlow C, Hollingsworth S. (2008). Bowel problems, self-care practices, and information needs of colorectal cancer survivors at 6 to 24 months after sphincter-saving surgery. Cancer Nursing, 31(5), 389-398.

Patel K, Bliss D.Z, Savik K. (2010). Health literacy and emotional responses related to fecal incontinence. Journal of Wound Ostomy Continence Nursing, 37(1), 73-79.

Pinar R. (2005). Reliability and construct validity of the SF-36 in Turkish cancer patients. Quality of Life Research, 14(1), 259-264.
Santoro G.A, Wieczorek A.P, Bartram C.I. (2010). Pelvic Floor Disorders Imaging and Multidisciplinary Approach to Management, Italy, Springer Science \& Business Media.

Siassi M, Hohenberger W, Lösel F, Weiss M. (2008). Quality of life and patient's expectations after closure of a temporary stoma. International Journal of Colorectal Disease, 23(12), 1207-1212.

Simpson M.F, Whyte F. (2006). Adjustment to colostomy: stoma acceptance stoma care and selfefficacy and interpersonal relationships. Journal of Advanced Nursing, 60(6), 627-635.

Sun V, Grant M, Wendel C.S, McMullen C.K, Bulkley J.E, Altschuler A ve ark. (2015). Dietary and behavioral adjustments to manage bowel dysfunction after surgery in long-term colorectal cancer survivors. Annals of Surgical Oncology, 22(13), 4317-4324.

Tan S.H, Liao Y.M, Lee K.C, Ko Y.L, Lin P.C. (2019). Exploring bowel dysfunction of patients following colorectal surgery: A cohort study. Journal of Clinical Nursing, 28(9-10), 1577-1584.

Taylor C, Morgan L. (2011). Quality of life after reversal of temporary stoma after rectal cancer treatment. European Journal of Oncology Nursing, 15 (1), 5966.

Timmermans S.L. (2016). Eliciting help-seeking behaviors in patients with fecal incontinence: Supporting timely access to treatment. Home healthcare now, 34(8), 424-433.

T.C. Sağlık Bakanlığı (2019). Sağlık İstatistikleri Yıllığ 2018. Ankara, Türkiye Cumhuriyeti Sağlık Bakanlığ Sağlık Bilgi Sistemleri Genel Müdürlüğü.

T.C. Sağlık Bakanlığı (2018).Türkiye Halk Sağlığı Genel Müdürlüğü Türkiye Kanser Kontrol Programı, Ankara, T.C. Sağlık Bakanlığı.

Wallner C, Lange M.M, Bonsing B.A, Maas C.P, Wallace C.N, Dabhoiwala N.F ve ark. (2008). Causes of fecal and urinary incontinence after total mesorectal excision for rectal cancer based on cadaveric surgery: a study from the Cooperative Clinical Investigators of the Dutch total mesorectal excision trial. Journal of Clinical Oncology, 26(27), 4466-4472.

Wang JY, Abbas MA. (2013). Current management of fecal incontinence. The Permanente Journal. 17(3), 65-73.

WHO (2018). Cancer. Cancer 12.09.2018 Erişim Tarihi: 12.03.2020, Erişim Adresi: https://www.who.int/ news-room/fact-sheets/detail/cancer

Yılmaz B, Aslan E. (2018). Fekal inkontinans ve hemşirelik yaklaşımı. SDÜ Sağlık Bilimleri Dergisi, 9(3), 39-44

Yin L, Fan L, Tan R, Yang G, Jiang F, Zhang C ve ark. (2018). Bowel symptoms and self-care strategies of survivors in the process of restoration after low anterior resection of rectal cancer. BMC Surgery, 18(1), 1-6. 